\title{
Vector density and the control of kala-azar in Bihar, India
}

\author{
V Kumar, S Kesari, AJ Kumar, DS Dinesh, A Ranjan, M Prasad, NK Sinha, R Kumar, P Das/+
}

Rajendra Memorial Research Institute of Medical Sciences, Indian Council of Medical Research, Agamkuan Patna-800 007, India

Bihar, India has been in the grip of kala-azar for many years. Its rampant and severe spread has made life miserable in most parts of the state. Such conditions require a comprehensive understanding of this affliction. The numbers coming out of the districts prone to the disease in the north and south Ganges have provided us with several startling revelations, as there are striking uniformities on both sides, including similar vegetation, water storage facilities, house construction and little change in risk factors. The northern areas have been regularly sprayed with DDT since 1977, but eradication of the disease appears to be a distant dream. In 2007 alone, there were as many as 37,738 cases in that region. In contrast, the southern districts of Patna and Nalanda have never had the disease in its epidemic form and endemic disease has been present in only some pockets of the two districts. In those cases, two rounds of spraying with DDT had very positive results, with successful control and no new established foci. In addition, an eleven-year longitudinal study of the man hour density and house index for the vector Phlebotomus argentipes demonstrated that they were quite high in Patna and Nalanda and quite low in north Bihar. Given these facts, an attempt has been made to unravel the role of $\mathrm{P}$. argentipes saliva (salivary gland) in the epidemiology of kala-azar. It was determined that patchy DDT spraying should be avoided for effective control of kala-azar.

Key words: Phlebotomus argentipes - DDT - salivary gland - house index - man hour density

The scourge of kala-azar is perilous in most parts of Bihar, which is divided into northern and southern regions by the Ganges. The riparian areas in 31 of its 38 districts are highly prone to this vector-borne disease, which is carried by the sandfly Phlebotomus argentipes, the only vector identified in India (Swaminath et al. 1942, Kumar et al. 2005). However, in addition to Bihar, there are others states in India where kala-azar (visceral leishmaniasis) occurs in its endemic form, including West Bengal, eastern Utter Predesh and Jharkhand. However, the figure from the northern districts of Bihar is astonishing, with 37,738 cases in 2007 alone. According to the National Vector Borne Disease Control Programme (NVBDCP), there are about 165 million people who are at risk of infection with kalaazar in Bihar Jharkhand, Uttar Pradesh and West Bengal. In 1970s, there was a sudden surge in the number of cases in Bihar, when the number rose to one lac; reports from different primary health centres ( $\mathrm{PHCs}$ ) indicated that 45,000 patients died in north Bihar. Since then, all PHCs in the region with endemic kala-azar have been sprayed liberally with DDT with effective results, as the number of cases went down remarkably. However, in 1998, the region was shaken by another epidemic, in which there were 77,102 cases (as per the report from the government of Bihar), although the actual figure is likely to be far more than that. Considering the situation, the state government declared kala-azar to be a

Financial support: RMRIMS (ICMR)

+Corresponding author: drpradeep.das@gmail.com

Received 11 September 2008

Accepted 23 September 2009 notifiable disease and the area was sprayed with two rounds of DDT, the first in February-March and the second in June-July (WHO workshop 1993). Since that time, DDT has been sprayed at regular intervals, but there has been little respite in the reports of new cases from areas in north Bihar. Interestingly, the number of cases diminished in the districts in the southern parts of the state, Patna and Nalanda, where DDT was rarely sprayed. The disease has erupted in its endemic form in some pockets of the region, but the number of cases has nearly disappeared following the proper spraying of DDT and careful treatment of those infected; no major outbreak has ever been reported in those areas. The scenario is quite different in north Bihar. Considering these two entirely different backgrounds, a longitudinal study was carried out in both areas to understand the mechanism of disease transmission and to suggest effective measures for its control. In addition, the study attempted to identify the role of sand fly density in the transmission of the disease, as there is a general belief that higher densities of $P$. argentipes are one of the main factors of transmission. Surprisingly, the areas with low sand fly density as a result of insecticide use were more vulnerable to the disease than were the areas with a high sand fly density.

\section{MATERIALS AND METHODS}

Two districts from the northern side of the Ganges, Vaishali and Muzaffarpur, were marked as the experimental areas, as kala-azar is highly endemic in these areas. Sand fly density was randomly monitored with the help of standard aspirators and hand-held threecelled torches in the early morning hours (Kumar et al. 1995). Two districts from the south, Patna and Nalanda, were selected as the control areas for monitoring sand fly density, as they are quite low endemic areas. 
This was done to assess the $P$. argentipes density in high and low endemic areas (Figure). Government agencies provided data on kala-azar cases and diagnosis was based on parasite presence in spleen/bone marrow aspirations, identified with rk39 kits as per the protocol provided by NVBDCP, government of India. In all of these areas, the $P$. argentipes density was monitored three times per year: pre monsoon, monsoon and post-monsoon. The densities were calculated using the total numbers of sand flies collected per man per hour. The house index (HI) was calculated as the percent of households positive for P. argentipes. Vaishali and Muzaffarpur are sprayed with DDT every year, whereas Patna and Nalanda are sprayed only focally around the affected areas. In Bihar, two rounds of spraying were carried out in the highly endemic areas, first in February-March and second in May-June (NICD 1993).

For purpose of socio-economic and house structure assessment, KAP was carried out in both areas. Similar efforts were made in peridomestic areas to determine the presence of water and vegetation. Migration of inhabitants was also not ignored. In the studied areas within the district of Patna, which was separated from north Bihar by a narrow band of water, people of the villages come and go regularly by boat.

Statistical analysis - Data was analysed using the statistical software SPSS ver. 15.0. All variables were tested for normality, so that suitable statistical tools could be used. The Z- test was used to examine the comparative difference of means for man hour density (MHD) and HI in the high and low endemic areas. One-way analysis of variance was used to test differences in MHD and HI among three types of houses: thatched, pucca and kathcha, in both areas separately. A two-way analysis of variance was used to compare MHD and HI among the three types of houses in the two endemic regions of villages of Bihar over 11 years of observations.

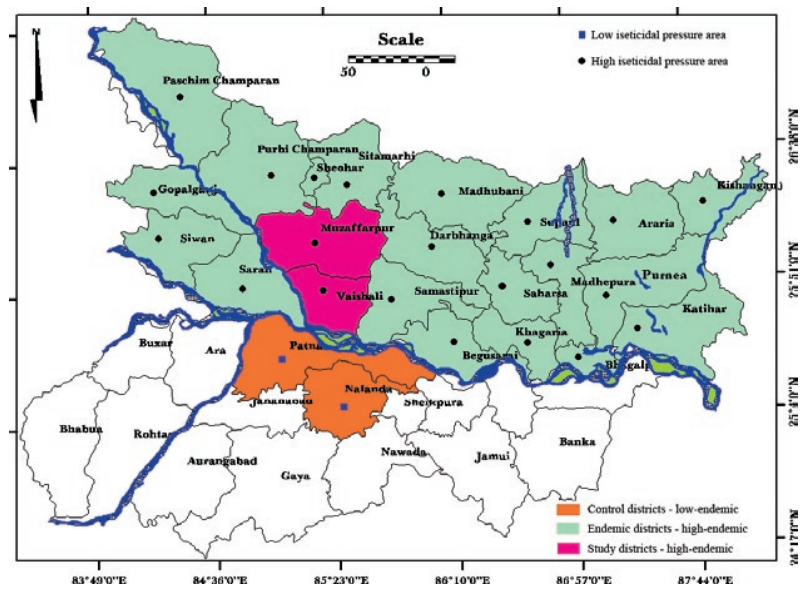

The study area in low endemic and high endemic districts.

\section{RESULTS AND DISCUSSION}

The results of sand fly collections for north and south Bihar are shown in Table I. Using MHD and HI, the low endemic regions in the south had a significantly higher $P$. argentipes density than the high endemic regions in north Bihar $(\mathrm{p}<0.001)$ (Table II). The density of $P$. argentipes was significantly higher in katcha houses than in pucca and thatched houses $(\mathrm{p}<0.001)$. It is possible that this is due to the presence of cracks and crevices with a high amount of humidity, which are essential conditions for breeding $P$. argentipes. The MHD of North Bihar varied between 5.36-10.96, with one exception in 2001, when it was just 13.57. The HI was also quite low, as it varied between 6.25-18.30. Paradoxically, the MHD and HI were quite high in the Patna and Nalanda districts, where the MHD was between 11.20-21.40 and the HI percentage in both districts was between 38 $55 \%$; this is possibly the result of frequent DDT spraying in north Bihar. However, in the Patna and Nalanda districts, the $P$. argentipes density was high because of occasional DDT spraying, which was done only on a focal basis in the event that kala-azar occurred in an endemic form. In 1994, there were 19 endemic cases in the village Gulmahiabagh, which had 205 houses. The village was sprayed just two times with DDT and once with malathion (SRES); the three total sprays were enough to contain the spread of the disease, as no cases have since been reported in that area. Another village, Chandi, with a population of 643 , reported six cases in the year 2000. The control measure in that village also consisted of two rounds of DDT with treatment of those infected; again, there were no further reports of cases. In yet another village in the Patna district, Jethuli, kala-azar occurred endemically from 1984-1985. Following DDT spraying and treatment of the cases, the area become totally free from the disease (Dhiman \& Sen 1991).

In examining studies of low socio-economic groups done in both areas, we found that the houses were made up of mud, soil and bamboo; some homes were made with walls of bricks and no plastering. However, with few exceptions, kala-azar cases also occurred in concrete houses in north and south Bihar. Both areas have some alluvial soil and some soft stem vegetation, such as banana, creepers and peridomestic vegetation, giving the terrain the same amount of risk factor for kala-azar transmission (Ranjan et al. 2005).

When combined, the facts from the above studies are puzzling, as there seems to be no reason why north Bihar suffers endlessly from kala-azar when both north and south Bihar have similar environmental situations and the presence of susceptible hosts. In addition, kala-azar establishes separate foci in north Bihar and is constantly present in endemic form there. In contrast, the Patna and Nalanda districts in south Bihar received a one-time control measure and the disease has been unable to establish new foci, though it remains with a few sporadic cases.

However, this could be explained in terms of sand fly density and saliva. It appears that sand fly saliva may play a crucial role in the epidemiology of kala-azar. In the district of Patna, the density of $P$. argentipes remains high 


\section{TABLE I}

Epidemiological and entomological aspects of the studied areas in north and south Bihar

\begin{tabular}{|c|c|c|c|c|c|c|c|c|c|c|}
\hline \multirow[b]{2}{*}{ Year } & \multirow{2}{*}{$\begin{array}{c}\text { Kala-azar } \\
\text { cases } \\
(\mathrm{n})\end{array}$} & \multicolumn{4}{|c|}{ North Bihar (Muzaffarpur and Vaishali) } & \multirow{2}{*}{$\begin{array}{c}\text { Kala-azar } \\
\text { cases } \\
\text { (n) }\end{array}$} & \multicolumn{4}{|c|}{ South Bihar (Patna and Nalanda) } \\
\hline & & MHD & $\begin{array}{l}\mathrm{HI} \\
(\%)\end{array}$ & $\begin{array}{c}\mathrm{RH} \\
(\% \max / \min )\end{array}$ & $\begin{array}{l}\text { Temperature } \\
\left({ }^{\circ} \mathrm{C} \max / \mathrm{min}\right)\end{array}$ & & MHD & $\begin{array}{l}\mathrm{HI} \\
(\%)\end{array}$ & $\begin{array}{c}\mathrm{RH} \\
(\% \mathrm{max} / \mathrm{min})\end{array}$ & $\begin{array}{l}\text { Temperature } \\
\left({ }^{\circ} \mathrm{C} \max / \mathrm{min}\right)\end{array}$ \\
\hline 1998 & 2,860 & 05.36 & 09.8 & $91-55$ & $32.5-17.0$ & 33 & 11.20 & 48.00 & $90-45$ & $33.5-15.0$ \\
\hline 1999 & 2,128 & 09.23 & 14.00 & $85-52$ & $31.0-16.6$ & 98 & 13.50 & 40.00 & $82-48$ & $32.0-16.0$ \\
\hline 2000 & 2,232 & 05.48 & 11.21 & $89-48$ & $33.6-16.2$ & 186 & 13.01 & 51.00 & $89-48$ & $33.5-15.2$ \\
\hline 2001 & 1,924 & 13.57 & 18.30 & $95-55$ & $32.5-16.5$ & 200 & 15.87 & 42.00 & $92-55$ & $32.0-15.5$ \\
\hline 2002 & 2,028 & 08.78 & 05.89 & $98-51$ & $31.8-15.5$ & 293 & 14.52 & 38.50 & $95-50$ & $32.8-14.5$ \\
\hline 2003 & 1,968 & 09.10 & 08.65 & $94-48$ & $34.7-14.5$ & 369 & 14.29 & 40.25 & $93-50$ & $36.7-14.8$ \\
\hline 2004 & 2,300 & 08.17 & 08.20 & $94-52$ & $36.0-19.6$ & 443 & 19.10 & 69.00 & $90-45$ & $36.5-18.6$ \\
\hline 2005 & 4,788 & 10.96 & 07.34 & $98-45$ & $33.63-21.2$ & 478 & 18.26 & 52.00 & $95-45$ & $33.5-18.2$ \\
\hline 2006 & 6,060 & 10.87 & 10.45 & $92-51$ & $36.0-20.0$ & 510 & 21.40 & 55.00 & $89-50$ & $36.5-16.0$ \\
\hline 2007 & 4,559 & 07.20 & 06.25 & $96-48$ & $34.2-16.5$ & 231 & 11.26 & 38.00 & $94-47$ & $34.2-15.5$ \\
\hline 2008 & 5,561 & 06.25 & 07.50 & $95-48$ & $35.5-17.5$ & 213 & 15.06 & 45.00 & $92-45$ & $36.5-14.5$ \\
\hline
\end{tabular}

HI: house index; MHD: man hour density; RH: relative humidity.

\section{TABLE II}

House structure of north Bihar and Patna district of studied village

\begin{tabular}{|c|c|c|c|c|c|c|c|c|}
\hline \multirow{3}{*}{$\begin{array}{l}\text { House } \\
\text { structure }\end{array}$} & \multicolumn{3}{|c|}{ North Bihar (Muzaffarpur and Vaishali districts) } & \multicolumn{3}{|c|}{ South Bihar (Patna and Nalanda districts) } & \multirow{3}{*}{$\begin{array}{l}\mathrm{p} \text { value } \\
\text { for MHD }\end{array}$} & \multirow{3}{*}{$\begin{array}{l}\mathrm{p} \text { value } \\
\text { for HI }\end{array}$} \\
\hline & \multirow{2}{*}{$\begin{array}{c}\text { Houses } \\
\text { n }(\%)\end{array}$} & \multicolumn{2}{|c|}{ Mean (SD) } & \multirow{2}{*}{$\begin{array}{c}\text { Houses } \\
\text { n (\%) }\end{array}$} & \multicolumn{2}{|c|}{ Mean (SD) } & & \\
\hline & & MHD & $\mathrm{HI}$ & & MHD & $\mathrm{HI}$ & & \\
\hline Thatched & $1,091(76.5)$ & $3.04(1.05)$ & $4.57(1.77)$ & $62(5)$ & $5.49(1.43)$ & $23.05(6.19)$ & & \\
\hline Pucca $^{g}$ & $234(16.4)$ & $1.49(0.53)$ & $1.34(0.50)$ & 293(23.4) & $1.80(0.49)$ & $5.36(2.72)$ & $<0.001^{2}$ & $<0.0014$ \\
\hline Katcha $^{h}$ & $101(7.1)$ & $4.14(1.34)$ & $3.86(1.58)$ & $897(71.6)$ & $7.95(2.08)$ & $18.75(3.09)$ & & $001^{\circ}$ \\
\hline Total & & $2.89(1.488)$ & $3.26(1.95)$ & & $5.07(2.94)$ & $15.72(8.71)$ & $<0.001^{c}$ & $<0.001^{f}$ \\
\hline
\end{tabular}

$a$ : one way ANOVA - among the type of house; $b$ : two way ANOVA - comparison of man hour density (MHD) among type of house and between two areas; $c$ : Z- test - between two areas; $d$ : one way ANOVA - among the type of house $e$ : two way ANOVA - comparison of house index (HI) among type of house and between two areas; $f$ : Z- test - between two areas; $g$ : brick and mud plaster or mud and soil: $h$ : concreate houses: pucca houses.

due to low insecticide use. As a result of the high sand fly density, the susceptible populations are frequently bitten and it has been demonstrated that a salivary gland protein from the sand flies provides protection against kala-azar infection (Velenzula et al. 2001, Silva et al. 2005).

As it happens, this continuous sand fly bite exposure may be the reason that new foci of kala-azar do not occur in the high density area. Indeed, the sand fly population remains depressed in north Bihar due to regular spraying with DDT and therefore, the population may not have the same exposure to sand fly bites. As a result, when the sand fly population resurges following the use of improper concentrations $(<5 \%)$ and patchy spraying of DDT, the sand flies are able to transmit the disease to the population previously unexposed to sand fly bites (susceptible host), even in low density areas. In this manner, new foci of kala-azar are created; this is exactly what has been happening in north Bihar. An example is the surge in the number of cases from 29,711 in 2006 to 37,738 in February 2007, during which DDT was sprayed in all 31 endemic districts of Bihar. It was likely caused by patchy spraying, which was noted while monitoring in most of the villages. Therefore, it is strongly suggested that DDT is sprayed in a thorough and proper manner; otherwise, $P$. argentipes may develop DDT resistance (Singh et al. 2001, Dhiman et al. 2003, Kishore et al. 2004) and new foci of kala-azar could arise. Our study indicated that a high vector density is not essential for disease transmission and transmission may occur successfully even in areas of low $P$. argentipes density, as it is epidemiologically more viable than at high density due to some immunological complexity and the involvement of saliva in kala-azar transmission. Thakur (2007) have also reported that the complete treatment 
and supervised intensive spray of DDT may eliminate kala-azar from rural Bihar. This study also indicates that further study of the role of $P$. argentipes saliva in the epidemiology of kala-azar is needed.

\section{ACKNOWLEDGEMENTS}

To SA Khan and AK Mandal, for their excellent technical assistance, and to State Health Society, Bihar for providing data of cases for the study.

\section{REFERENCES}

Dhiman RC, Raghavendra K, Kumar V, Keasri S, Kishore K 2003. Susceptibility status of Phlebotomus argentipes to insecticide in districts Vaishali and Patna. J Commun Dis 35: 49-51.

Dhiman RC, Sen AB 1991. Epidemiology of kala-azar in rural Bihar (India) using village as a component unit of study. Indian J Med Res 93: 155-160.

Kishore K, Kumar V, Kesari S, Bhattacharya SK, Das P 2004. Susceptibility of Phlebotomus argentipes against DDT in endemic districts of North Bihar. India J Commun Dis 36: 41-44.

Kumar V, Bimal S, Kesari S, Kumar AJ, Bagchi AK, Akbar MA, Kishore K, Bhattacharya SK, Das P 2005. Evaluation of a dotimmunoblot assay for detecting leishmanial antigen in naturally infected Phlebotomus argentipes (Diptera: Psychodidae). Ann Trop Med Parasitol 99: 1-6.

Kumar V, Kesari SK, Sinha NK, Palit A, Ranjan A, Kishore K, Saran R, Kar S 1995. Field trail of an ecological approach for the con- trol of Phlebotomus argentipes using mud \& lime plaster. Indian J Med Res 101: 154-156.

NICD - National Institute of Communicable Diseases, Directrate of General of Health Services 1993. Proceedings of workshop on entomological and vector control aspects of kala-azar, 22 Sham Nath Marg, Delhi, p. 54.

Ranjan A, Sur Dipika, Sing VP, Siddique NA, Manna B, Lal CS, Sinha PK, Kishore K, Bhattacharya SK 2005. Risk factors for India kala-azar. Am J Trop Med Hyg 73: 74-78.

Silva F, Gomes R, Prates D, Miranda JC Andrade B, Barral-Netto M, Barral A 2005. Inflammatory cell infiltration and high antibody production in BALB/c mice caused by natural exposure to Lutzomyia longipalpis bites. Am J Trop Med Hyg 72: 94-98.

Singh R, Das RK, Sharma SK 2001. Resistance of sandflies to DDT in kala-azar endemic districts of Bihar in India. Bull WHO 79: 793.

Swaminath CS, Short HE and Anderson LAP 1942. Transmission of Indian kala-azar to man by the bite of $P$. argentipes. Ind $J$ Med Res 30: 473-477.

Thakur CP 2007. Anew strategy for elimination of kala-azar from rural Bihar. Indian J Med Res 126: 447-451.

Valenzuela GJ, Belkaid Y, Garfeild MK, Mendez S, Kamhawi S, Rowton ED, Sacks DL, Ribeiro JM 2001. Toward a defined antileishmania vaccine targeting vector antigens: characterization of a protective salivary protein. $J$ Exp Med 194: 331-342. 